\title{
CORRIGENDUM
}

\section{the mine ban treaty, new diplomacy and human security ten years later javier alcalde villacampa}

doi:10.1057/eps.2009.23

\section{Correction to:}

European Political Science (2008) 7(4), 519-529.

doi: $10.1057 /$ eps.2008.30

\begin{abstract}
The author apologises for the omitted reference and incorrectly phrased sentence that appears on page 521 :

'Indeed, in any ideal new diplomacy process, there is a facilitating condition that reduces transaction costs: the shared background of key individuals in policy-making positions and NGO activists, which enables communication between the two sides of the like-minded coalition. Sometimes, this is made possible by the opening of positions within a government to former NGO members'.

This sentence should have been correctly written as

'Indeed, in any ideal new diplomacy process, there is an enabling condition that reduces transaction costs: "the shared background of key individuals in policymaking positions and NGO activists facilitate[s] communication between the two sides of the like-minded coalition ... [which sometimes is] made possible by the opening of government positions to former NGO members". (Petrova, 2007:19)'
\end{abstract}

